\title{
국내 개발재원 현황: 국내 ODA 재원현황
}

목 차

1. $\mathrm{ODA}$ 재원의 정의

2. 국내 $\mathrm{ODA}$ 재원현황

3. 향후 국내 ODA 재원전망

\section{ODA 및 ODA 재원의 정의}

$\mathrm{ODA}$ (Official Development Assistance)의 일반적인 정의는 $\mathrm{OECD} / \mathrm{DAC}$ 에서 정한 수원국 목록에 있는 국가 및 지역, 또는 다자간 개발협력기구에 제공되는 자금 또는 기술협력이다. 위의 ODA 의 정의에 따라 $\mathrm{OECD}$ 에서 정한 $\mathrm{ODA}$ 의 세부조건으로는 (1) 중앙 및 지방정부, 기타공공집행기관 등에 의한 제공 (2) ODA 수원국의 경제· 사회 발전 및 복지증진목적 (3) 증여율 $25 \%$ 이상인 양허성 조건의 자금이어야 한다. ${ }^{1)}$

상기의 $\mathrm{ODA}$ 정의에 따른 $\mathrm{ODA}$ 재원의 정의는 개도국 발전을 위한 자금 및 기술협력을 위한 무상, 유상, 다자원조를 수행하는 중앙 및 지방정부, 기타 공공기관의 예산 및 기금을 말한다.

1) 한국국제협력단. 2013, ${ }^{\circledR}$ 국제개발협력의 이해 $p 27-29$ 」 


\section{2. 국내 ODA 재원현황}

\section{1) ODA 정책수립 및 재원편성}

국내 $\mathrm{ODA}$ 에 관한 정책조정은 국무총리를 위원장으로 하는 국제개발협력위원회가 주관하고 있으며, 무상원조 및 국제금융기구협력을 제외한 다자원조는 외교부가 주관하고 유상원조 및 국제금융기구협력에 관한 다자원조는 기획재정부가 주관하고 있다. ${ }^{2)} \mathrm{ODA}$ 정책조정과는 별개로 $\mathrm{ODA}$ 재원의 심의 편성은 기획재정부(예산실)가 담당하여 복수의 심의구조를 가지고 있으며, 최종적으로 국회의 심의 · 의결을 통하여 확정된다.

\section{2) ODA 재원현황}

\section{2014년 ODA 재원현황-3)}

최근 4년간 우리나라의 $\mathrm{ODA}$ 지원현황을 살펴보면, 매년 점진적으로 증가하는 것을 볼 수 있다 (연평균 성장률 7.7\%). 특히 2012년에 처음으로 ODA 2조원 시대를 열었으며, 2014년 정부(안) 편성결과 2조 2,583 억원이다. $\mathrm{ODA} / \mathrm{GNI}$ 비율도 점진적으로 확대되고 있어 2014년은 전체 $\mathrm{GNI}$ 의 $0.16 \%$ 로 나타났다.

2014년 ODA 재원을 지원 형태별로 분류하면, 다자 ODA 재원은 6,632억원으로 전년대비 약 $8.5 \%$ (606억원) 감소하였다. 이는 우리나라의 UN 정규 예산 및 $\mathrm{PKO}$ 예산 분담률이 2013년 전체 $\mathrm{UN}$ 예산의 2.26\%에서 2014년 1.994\%로 자연감소 한 결과이다. ${ }^{4)}$ 다자 ODA 재원이 다소 감소한 것과는 달리, 양자 $\mathrm{ODA}$ 재원은 1 조 5,951 억원으로 전년대비 약 $12.2 \%$ (1,729억원) 상승하였다. 유상 $\mathrm{ODA}$ 재원은 7,533억원으로 전년대비 847억원(12.7\%)증가 하였고, 무상 ODA 재원편성은 8,418억원으로 2013년 대비 882억원(11.7\%)이 증액되었다.

〈표 1〉2011 2014년간 ODA 재원현황

(단위: 억원, \%)

\begin{tabular}{c|r|r|r|r|r}
\hline 구 분 & \multicolumn{1}{|c|}{ 2011년 } & \multicolumn{1}{c|}{ 2012년 } & \multicolumn{1}{c|}{ 2013년 } & \multicolumn{1}{c|}{ 2014년(안) } & 연평균 증가율(\%) \\
\hline ODA총액=11+2 & 18,088 & 20,609 & 21,470 & 22,583 & 7.7 \\
\hline$\square$ 다자 & 5,866 & 7,810 & 7,248 & 6,632 & 4.2 \\
\hline 2 양자 (1)+(2) & 12,222 & 12,799 & 14,222 & 15,951 & 9.3 \\
\hline (1) 유상 & 6,048 & 6,152 & 6,686 & 7,533 & 7.6 \\
\hline
\end{tabular}

\footnotetext{
2) 국제개발협력기본법 제7조, 제9조

3) 2014년 데이터는 정부(안) 수치로 최종국회 심의확정 예산과는 차이가 있을 수 있음

4) 국회 외교통일위원회. 2013. 『2014년 회계연도 외교부 소관 예산안 및 기금운용 계획안 검토보고서」, p20
} 


\begin{tabular}{c|r|r|r|r|r}
\hline 구 분 & 2011년 & 2012년 & 2013년 & 2014년(안) & 연평균 증가율(\%) \\
\hline (2) 무상 & 6,174 & 6,647 & 7,536 & 8,418 & 10.9 \\
\hline ODA/GNI 비율 & $0.12 \%$ & $0.14 \%$ & $0.15 \%$ & $0.16 \%$ & - \\
\hline
\end{tabular}

출처: 국회 예산결산특별위원회 2014년 예산안 및 기금운용계획안 검토보고서

\section{ㅁ 각 집행 부처별 $\mathrm{ODA}$ 재원현황}

우리정부의 2014년도 ODA 재원의 정부(안) 편성결과를 살펴보면, 2013년 대비 1,113억원이 증가한 2 조 2,583 억원이 편성되어, 전년대비 약 $5.2 \%$ 증액 편성되었다.

무상원조를 주관하는 외교부가 1 조 731 억원으로 전체 $\mathrm{ODA}$ 재원의 $47.5 \%$ 를 차지하였으며, 유상원조를 담당하는 기획재정부가 9,170 억원으로 전체 재원의 $40.6 \%$ 를 차지하였다. 현행 ODA를 수행하는 29 개 각 정부부처 및 위원회 가운데 국무조정실, 기획재정부, 문화체육관광부, 해양수산부, 교육부, 농촌진흥청 등 15 개 부처는 전년대비 ODA 재원편성이 증가하였고 ${ }^{5}$ 외교부 및 고용노동부 등 8개 부처는 전년대비 감소하였으며, 법무부 및 산업통상자원부 등 5 개 부처는 전년과 동일하게 $\mathrm{ODA}$ 재원이 편성되었다.

\section{〈표 2〉 2012 2014년간 각 부처별 ODA 재원현황6)}

(단위: 억원)

\begin{tabular}{c|r|r|r|r}
\hline 부 처 명 & 12년 예산 & 13년 예산 & 14년 예산(안) & 증감액 \\
\hline 계 & 20,609 & 21,470 & 22,583 & 1,113 \\
\hline 국회사무처 & 3 & - & - & - \\
\hline 중앙선거관리위원회 & 2 & 4 & 4 & 0 \\
\hline 국무조정실(구.국무총리실) & 65 & 56 & 66 & 10 \\
\hline 기획재정부 & 7,382 & 8,026 & 9,170 & 1,144 \\
\hline 교육부(구.교육과학기술부) & 555 & 533 & 573 & 40 \\
\hline 외교부(구.외교통상부) & 10,836 & 10,907 & 10,731 & $\triangle 176$ \\
\hline 법무부 & 11 & 13 & 13 & 0 \\
\hline 안전행정부(구.행정안전부) & 244 & 225 & 234 & 9 \\
\hline 문화체육관광부 & 50 & 85 & 107 & 22 \\
\hline 농림축산식품부(구.농림수산식품부) & 310 & 287 & 283 & $\triangle 4$ \\
\hline 해양수산부 & - & 17 & 27 & 10 \\
\hline 국토교통부(구.국토해양부) & 1 & 1 & 60 & 59 \\
\hline
\end{tabular}

5) 국토교통부 사업 증액은 “13년도 ODA사업으로 분류하지 않았던 사업을” 14 년부터 ODA 사업으로 분류하여 증가하였음

6) 국토교통부 사업 증액은 “13년도 ODA사업으로 분류하지 않았던 사업을” 14 년부터 ODA 사업으로 분류하여 증가하였음 


\begin{tabular}{c|r|r|r|r}
\hline 부 처 명 & 12년 예산 & 13년 예산 & 14년 예산(안) & 증감액 \\
\hline 산업통상자원부(구.지식경제부) & 163 & 110 & 110 & 0 \\
\hline 보건복지부 & 308 & 357 & 352 & $\Delta 5$ \\
\hline 환경부 & 52 & 79 & 74 & $\Delta 5$ \\
\hline 고용노동부 & 159 & 131 & 119 & $\Delta 12$ \\
\hline 여성가족부 & 59 & 63 & 62 & $\Delta 1$ \\
\hline 국가보훈처 & 1 & 2 & 2 & 0 \\
\hline 방송통신위원회 & 83 & - & - & - \\
\hline 미래창조과학부 & - & 201 & 206 & 5 \\
\hline 공정거래위원회 & 2 & 2 & 2 & 0 \\
\hline 국민권익위원회 & 1 & 1 & 1 & 0 \\
\hline 관세청 & 23 & 32 & 34 & 2 \\
\hline 통계청 & 7 & 9 & 7 & $\Delta 2$ \\
\hline 경찰청 & 27 & 14 & 15 & 1 \\
\hline 문화재청 & 11 & 18 & 20 & 2 \\
\hline 농촌진흥청 & 126 & 144 & 156 & 12 \\
\hline 산림청 & 71 & 98 & 103 & 5 \\
\hline 특허청 & 17 & 18 & 19 & 1 \\
\hline 기상청 & 0.1 & 1 & 3 & 2 \\
\hline 원자력안전위원회 & 33 & 36 & 33 & $\Delta 3$ \\
\hline 식품의약품안전처(구심의약품안전청) & 6 & - & - & - \\
\hline & & 19 & & \\
\hline
\end{tabular}

출처: 국회 예산결산특별위원회 2014년 예산안 및 기금운용계획안 검토보고서

\section{ㅁ 분야별 ODA 재원 집행현황7)8)}

우리정부의 2008 2012년도 분야별 ODA 재원의 집행현황을 보면, 사회 인프라 서비스, 경제 인프라 서비스 및 생산 · 산업 부분의 ODA 집행액 평균이 전체의 $81.7 \%$ 로 절대 다수를 차지하고 있다.

MDGs Goal 2,4,5번에 해당하고 개도국의 개발 수요가 가장 높은 사회 인프라 서비스분야에 평균 $45.1 \%$ 로 가장 많은 $\mathrm{ODA}$ 재원이 투입 되었다. 세부 집행내역은 교육 $15.1 \%$, 보건 $11.9 \%$, 인구정책 · 생식보건 $0.8 \%$, 수자원·위생 $7.7 \%$, 공공행정·시민사회 $8.1 \%$ 및 기타 사회 인프라 $1.5 \%$ 로 나타나고 있다. 사회 인프라 서비스에 뒤이어 개도국의 경제발전 인프라구축을 위한 경제 인프라 서비스 분야는 평균 $26.9 \%$ 씩 재원이 집행되었으며, 교통 - 물류 $16.3 \%$, 통신 $6.7 \%$, 에너지 $3.4 \%$, 금융 - 재무 서비스 $0.2 \%$ 및 비즈니스. 기타 서비스에 각각 $0.2 \%$ 의 재원을 집행하였다. 생산 · 산업분야는 ODA 재원 집행액의 평균 $9.7 \%$ 를 차지하고 있으며 농림어업 $6.7 \%$, 산업광업건설 $1.6 \%$, 통상정책 · 조정 $1.3 \%$ 및 관광분야에 $0.1 \%$ 를 집행하였다.

7) 2014년 데이터는 정부(안) 수치로 최종국회 심의확정 예산과는 차이가 있을 수 있음

8) 국제개발협력위원회: 한국ODA 분야별 지원실적(http://www.odakorea.go.kr) 
〈그림 1〉2008 2012년간 각 분야별 ODA 재원배분

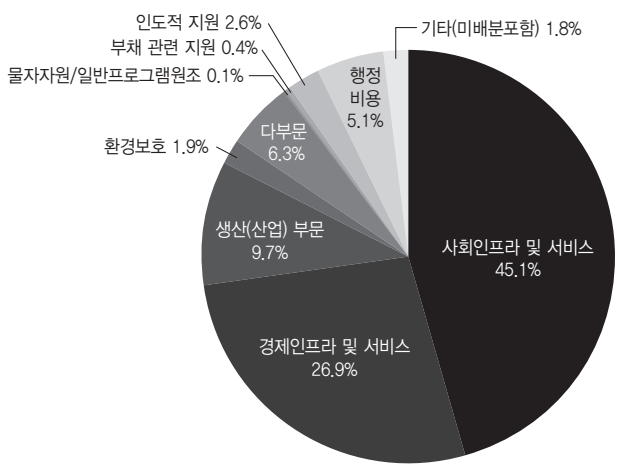

\section{3) 각국의 ODA 재원 증감현황}

대한민국을 비롯한 OECD/DAC 회원국의 2009 2012년 ODA 재원 증감추이를 살펴보면, 최근 4 년간 평균 증가율이 $-0.25 \%$ 로 나타났다. 최근 4년간 ODA 재원이 증가한 국가는 대한민국을 비롯한 14 국이며, 그리스 및 스페인 등 12 국은 최근 4년간 ODA재원이 감소하였다.

2008년 미국의 서브프라임 모기지 사태에서 비롯한 국제경제위기로 2009년 OECD/DAC 국가의 ODA 재원은 전년대비 6.9\%가 감소하였다. 2010년 및 2011년은 대한민국, 호주, 뉴질랜드, 스웨덴 등을 중심으로 미국발 경제위기를 서서히 회복하여 ODA재원 증가율을 선도하였으며 전년대비 $6 \%$ 대의 증가폭을 보였다. 하지만, 2011년 이후 유럽 재정위기 여파로 전통적 공여국인 OECD/DAC 소속 유럽국가 대부분의 ODA재원이 감소되어 2012년 OECD/DAC 국가의 ODA재원은 2011년 대비 $7.0 \%$ 감소하는 등 각 공여국의 경제상황에 따라 $\mathrm{ODA}$ 재원의 증감 폭이 넓게 나타났다.

〈표 3〉2009 2012년간 각 국가별 ODA 재원 증가율 현황

(단위: \%)

\begin{tabular}{c|r|r|r|r|r}
\hline 국가 & \multicolumn{1}{|c|}{2009} & \multicolumn{1}{c|}{2010} & \multicolumn{1}{c|}{2011} & \multicolumn{1}{c|}{2012} & \multicolumn{1}{c}{ 4년간 평균 } \\
\hline 대한민국 & 1.7 & 43.8 & 12.8 & 17.1 & 18.87 \\
\hline 호주 & $\Delta 6.5$ & 38.5 & 28.7 & 10.5 & 17.80 \\
\hline 스위스 & 13.4 & $\triangle 0.4$ & 32.6 & $\triangle 0.9$ & 11.16 \\
\hline 뉴질랜드 & $\Delta 11.1$ & 10.7 & 23.9 & 7.4 & 7.71 \\
\hline 캐나다 & $\Delta 16.6$ & 30.4 & 4.7 & 4.0 & 5.62 \\
\hline 영국 & $\triangle 1.9$ & 15.7 & 6.0 & $\triangle 1.3$ & 4.63 \\
\hline 노르웨이 & 1.9 & 7.1 & 8.8 & $\triangle 0.0$ & 4.44 \\
\hline
\end{tabular}




\begin{tabular}{|c|c|c|c|c|c|}
\hline 국가 & 2009 & 2010 & 2011 & 2012 & 4년간 평균 \\
\hline 폴란드 & 0.6 & 0.8 & 10.4 & 5.0 & 4.20 \\
\hline 미국 & 9.1 & 5.3 & 1.4 & $\triangle 1.0$ & 3.68 \\
\hline 핀란드 & 10.7 & 3.3 & 5.5 & $\triangle 6.1$ & 3.33 \\
\hline 스웨덴 & $\triangle 3.9$ & $\triangle 0.3$ & 23.6 & $\triangle 6.4$ & 3.24 \\
\hline 프랑스 & 15.5 & 2.5 & 0.6 & $\triangle 6.9$ & 2.95 \\
\hline 일본 & $\triangle 1.4$ & 16.4 & $\triangle 1.7$ & $\triangle 3.1$ & 2.55 \\
\hline 룩셈부르크 & $\triangle 0.1$ & $\triangle 2.9$ & 1.6 & 5.6 & 1.07 \\
\hline 벨기에 & 9.4 & 15.1 & $\triangle 6.5$ & $\triangle 18.0$ & 0.00 \\
\hline 포르투갈 & $\triangle 17.3$ & 26.6 & 9.1 & $\triangle 19.9$ & $\triangle 0.39$ \\
\hline 덴마크 & 0.2 & 2.2 & 2.1 & $\triangle 7.3$ & $\triangle 0.69$ \\
\hline 독일 & $\triangle 13.6$ & 7.5 & 8.5 & $\triangle 7.0$ & $\triangle 1.14$ \\
\hline 체코 & $\triangle 13.8$ & 6.0 & 10.1 & $\triangle 12.4$ & $\triangle 2.56$ \\
\hline 슬로바키아 & $\triangle 17.9$ & $\triangle 2.2$ & 16.7 & $\triangle 9.2$ & $\triangle 3.16$ \\
\hline 네덜란드 & $\triangle 8.1$ & $\triangle 1.1$ & $\triangle 0.2$ & $\triangle 12.9$ & $\triangle 5.58$ \\
\hline 오스트리아 & $\triangle 33.4$ & 5.8 & $\triangle 8.0$ & 0.1 & $\triangle 8.87$ \\
\hline 이탈리아 & $\triangle 32.2$ & $\triangle 9.1$ & 44.4 & $\triangle 39.0$ & $\triangle 8.98$ \\
\hline 아일랜드 & $\triangle 24.3$ & $\triangle 11.0$ & 2.1 & $\triangle 11.4$ & $\triangle 11.16$ \\
\hline 아이슬란드 & $\triangle 28.9$ & $\triangle 16.5$ & $\triangle 11.1$ & 1.6 & $\triangle 13.70$ \\
\hline 그리스 & $\triangle 13.6$ & $\triangle 16.4$ & $\triangle 16.3$ & $\triangle 23.7$ & $\triangle 17.53$ \\
\hline 스페인 & $\triangle 4.1$ & $\triangle 9.6$ & $\triangle 29.9$ & $\triangle 53.3$ & $\triangle 24.23$ \\
\hline 연도평균 & $\triangle 6.9$ & 6.2 & 6.7 & $\triangle 7.0$ & $\triangle 0.25$ \\
\hline
\end{tabular}

출처: OECD/DAC 통계(2013년 OECD/DAC에 가입한 슬로바키아, 아이슬란드, 체코, 폴란드 포함)

\section{3. 향후 국내 ODA 재원전망}

\section{1) $\mathrm{ODA}$ 재원의 정의 및 현황}

$\mathrm{ODA}$ 재원의 정의는 중앙정부, 지방정부 또는 공공기관의 개도국 사회 경제발전을 위해 투입되는 자금과 기술협력을 위한 예산 및 기금을 말한다. 우리정부의 ODA 정책조정은 국무총리를 위원장으로 하는 국제개발협력위원회에서 소관 하지만, ODA 재원의 편성은 기획재정부가(예산실) 담당하는 이원적 체제로 운영된다. ODA 재원의 집행은 29 개의 정부부처 및 위원회에서 각 부처의 특수성을 반영하여 고유의 사업을 실시하고 있다. 
$\mathrm{OECD} / \mathrm{DAC}$ 국가들의 최근 4년간 $\mathrm{ODA}$ 재원 증감 현황을 살펴보면, 최근 발생한 미국 및 유럽의 경제위기에 따라 증감폭이 높게 나타나고 있는 것을 볼 수 있다. 대한민국은 2009년 OECD/DAC 가입 후 ODA 재원을 지속적으로 확대하고 있으며 2014년 ODA/GNI 대비 0.16\%까지 ODA 재원을 확대하였다.

\section{2) 향후 ODA 재원전망}

당초 우리 정부는 국제개발협력 선진화 방안(2010.10)9) 및 제4차 원조효과 고위급 포럼(HLF4/2011.11)에서 2015년까지 ODA/GNI 비율을 0.25\%까지 올리기로 목표하였으나, 이에 대해서는 현실적으로 달성이 불투명하다는 의견이(1011)12) 지배적이다. 그럼에도 불구하고 우리정부는 개도국 발전을 위한 ODA 지속 확대라는 정책기조를 충실히 수행하고 있으며 ${ }^{13)}$, 특히 유럽을 중심으로 한 전통적 공여국이 외부적 경제 불안요소에 기인하여 $\mathrm{ODA}$ 재원을 축소하고 있는 반면, 우리정부는 지속적으로 $\mathrm{ODA}$ 재원을 확대하고 있다. 아울러, 박근혜 정부는 “ODA 재원의 지속 확대"를 외교분야 국정과제로 집중관리하고 있으며 ${ }^{14)}$, 국내외 경제여건을 감안하여 향후 점진적인 확대를 계획하고 있다. 향후 ODA 재원의 증감 전망은 제2차 국제개발협력 기본계획(2016-2020) 수립 시 보다 구체화 될 전망이다.

\section{3) 혁신적 ODA 재원 발굴논의}

타국의 ODA 재원감소 경향에도 불구하고 다행히 우리나라는 지속적으로 확대기조에 있다. 하지만 우리정부의 ODA 재원은 국가재정을 수반하는 전통적 의미의 ODA라고 할 수 있다. 이러한 $\mathrm{ODA}$ 재원은 필연적으로 교육, 복지 또는 국방과 같은 국내 재정수요와 상충되어, 국가재정 감축 상황에서의 $\mathrm{ODA}$ 재원은 정책적 우선순위에서 멀어져 축소가 불가피하다. 아울러 $\mathrm{ODA}$ 재원의 특성상 성과보다는 투입에 초점이 맞추어져 있다는 비판15)이 있는 등 ODA 재정의 확대는 그 한계가 분명하다.

최근 $\mathrm{ODA}$ 공여국 정부, 시민단체 및 학계에서는 $\mathrm{ODA}$ 재원확대의 어려움을 해소하고 $\mathrm{ODA}$ 재원을 효과적으로 이용하기 위한 시도로 혁신적, 융복합적 ODA 재원발굴에 대한 논의가 활발하게 이루어지고 있다. 이러한 국제적 논의의 흐름에 따라 우리나라도 전통적 $\mathrm{ODA}$ 를 탈피한 혁신적 재원마련을 위하여 사업자 보증제도 및 혁신적 민관협력 사업 등과 같은 사업을 추진하고 있다.

\footnotetext{
9) 제4,7차 국제개발협력위원회 의결안건

10) 국회 예산결산특별위원회. 2013."2014년 예산안 및 기금운용 계획안-총괄 p348」

11) 국회 예산정책처. 2013.『2014년도 정부 성과계획 평가 p270」

12) 국회 입법조사처. 2014.'이슈와 논점 제77호-Post 2015와 한국 ODA정책의 개선과제」

13) 제 17 차 국제개발협력위원회 의결안건

14) 박근혜 정부 국정과제 제133번

15) 윌리엄 이스틀리. 2011.`세계의 절반구하기 p290-293」
} 
사업자 보증제도란, 개도국에서 대규모 사업을 추진하는 특수사업법인(SPC: Special Project Company)이 자금을 차입 할 때, 개도국의 신용등급이 낮아 대출이 불가능 하거나 금리가 높게 형성되지 않도록 $\mathrm{ODA}$ 재원을 투입하여 $\mathrm{SPC}$ 가 자금을 조달하는 금융기관에 보증을 해주는 제도이다. 사업자 보증 제도를 통하여 대규모의 자금이 필요한 개도국 인프라 구축사업의 실시가 가능하게 되어, 비교적 적은 $\mathrm{ODA}$ 재원을 발판으로 대규모 사업이 가능하게 되는 레버리지(leverage)효과를 얻을 수 있다.

혁신적 민관협력 사업이란 기존의 일방향의 개발협력 CSO 예산지원 사업이 아닌 CSO, 학계 및 기업과 다양한 사업모델을 공동추진하는 사업이다. 다양한 개발협력 주체와 소통 - 융합하여 개도국에 가장 필요한 분야에, 최적화된 전달방법으로 지속가능성이 높은 사업을 지원하여 $\mathrm{ODA}$ 재정 부담을 낮추고 $\mathrm{ODA}$ 사업 효과성을 극대화 시키는 효과를 볼 수 있다. 아울러 개도국에 진출한 기업과 공동으로 사회적 가치 창출(CSV: Creating Shared Value)사업을 확대하여 ODA 재정투입이 기업 및 사회와 공동으로 성장 할 수 있는 모델을 생산하는 효과를 얻을 수 있다.

\section{4) 중기 ODA 재원전망에 따른 향후 정책방향}

우리 정부는 2009년 OECD/DAC 가입이후 제1차 “국제개발협력 기본계획”을 수립하여 20102015년 간 ODA 재원의 확대계획을 수립하였고, 동 기간 동안 타 공여국의 재원축소에도 불구하고 지속적으로 확대해왔다. 우리정부는 ODA 재원의 양적 확대기였던 제 1 차 기간 동안의 경험 및 교훈을 발판으로 제2차 “국제개발협력 기본계획"이 집행되는 2016-2020년은 과감한 ODA 재원 확대보다는 점진적인 재원확대와 동시에 집행체계 개선 및 지출 효율화를 통한 ODA 재정집행의 질적 확대를 목표할 것으로 예측된다. 아울러, 1 차 기간과 비교하여 우리나라의 경제성장에 대한 예측이 불분명하고 국민들의 복지수요가 높아져 2 차 기간 동안의 재원 증가율은 1 차 기간을 상회하기는 어려울 것으로 예측된다. 따라서 한정된 재원을 최대한 효율적으로 집행 할 수 있는 체계 구축이 필요하고, 한정된 $\mathrm{ODA}$ 재원에 국한되지 않고 개도국 개발협력사업을 최대한 확대 할 수 있도록 민간을 적극적으로 참여시키는 혁신적 재원발굴이 필요하다. 


\section{〈참고문헌〉}

한국국제협력단. 2013.『국제개발협력의 이해 개정판』, 한울아카데미.

윌리엄 이스틀리. 2011.『세계의 절반구하기』, 미지북스.

국회 외교통일위원회. 2013. ${ }^{\circledR 2014}$ 년 회계연도 외교부 소관 예산안 및 기금운용 계획안 검토보고서 $\mathrm{p} 20$, 국회.

국회 예산결산특별위원회. 2013. 『2014년 예산안 및 기금운용 계획안-총괄』, 국회.

국회 예산정책처. 2013『2014년도 정부 성과계획 평가 』, 국회

제II장

국회 입법조사처. 2014. ${ }^{『 P o s t ~ 2015 ㅇ ㅘ ~ ㅎ ㅏ ㄴ ㄱ ㅜ ㄱ ~ O D A ㅈ ㅓ ㅇ ㅊ ㅐ ㄱ ㅇ ㅢ ~ ㄱ ㅐ ㅅ ㅓ ㄴ ㄱ ㅘ ㅈ ㅔ 』, ~ 〈 ㅇ ㅣ ㅅ ㅠ ㅇ ㅘ ~ ㄴ ㅗ ㄴ ㅈ ㅓ ㅁ 〉, ~ ㅈ ㅔ 77 ~}$ 호, 국회.

OECD/DAC. 2012. ${ }^{\circledR O D C E / D A C ~ P e e r ~ R e v i e w ~ 2012-K O R E A 』, ~ O E C D . ~}$

수출입은행 ODA 통계사이트: http://www.edcfkorea.go.kr/edcf/info/oda/system. jsp

국제개발협력위원회 사이트: http://www.odakorea.go.kr 